\title{
Preventing misdiagnosis in amniotic band sequence: a case report
}

\author{
Cristiane Rúbia Ferreiraa , Cibelle Freitas Pinto Limab, \\ Ana Maria Andrello Gonçalves Pereira de Meloc
}

Ferreira CR, Lima CFP, Melo AMAGP. Preventing misdiagnosis in amniotic band sequence: a case report. Autopsy Case Rep [Internet]. 2013;3(1): 15-22. http://dx.doi.org/10.4322/acr.2013.003

\section{ABSTRACT}

Amniotic band sequence (ABS) is an uncommon and heterogeneous congenital disorder caused by entrapment of fetal parts by fibrous amniotic bands, causing distinctive structural abnormalities involving limbs, trunk, and craniofacial regions. The incidence ranges between $1 / 1200$ and $1 / 15,000$ live births, but is higher in stillbirths and previable fetuses. The intrinsic theory attributes the constriction band syndrome as an inherent development defect of embryogenesis while the extrinsic theory proposes that an early amnion rupture is responsible for the adherent bands. It is also suggested that amputations and constriction rings might be due to vascular disturbances. Anomalies resulting from amniotic bands are quite variable and sometimes may simulate chromosomal abnormalities. The authors report a case of a 36-week-gestation male neonate who lived for 29 hours after a vaginal delivery with an Apgar score of 8/9/9. The mother was primipara, and the prenatal was uneventful except for two episodes of urinary tract infections. The newborn examination depicted multiple anomalies characterized by exencephaly, bilateral labial cleft with distorted nostrils and palate cleft. There was also facial skin tag band, exophthalmos with hypoplasia of the eyelids. The limbs showed distal amputation of the fingers in both hands and feet, oligodactyly associated with syndactyly in the left foot, ring constriction in the right leg, the presence of right hyperextension, and clubfoot. The upper limbs showed length discrepancies. Karyotype analysis was normal at $46 \mathrm{XY}$. The authors conclude that the recognition of the malformations secondary to $A B S$ is important in genetic counseling to prevent misdiagnosis between chromosomal and secondary disruption disorders.

Keywords: Amniotic Band Sequence; Cleft Palate; Congenital Abnormalities; Neural Tube Defects.

\footnotetext{
${ }^{a}$ Anatomic Pathology Service - Hospital Universitário - Universidade de São Paulo, São Paulo/SP - Brazil.

${ }^{\text {b }}$ Department of Pathology - Faculdade de Medicina - Universidade de São Paulo, São Paulo/SP - Brazil.

${ }^{c}$ Department of Pediatrics - Hospital Universitário - Universidade de São Paulo, São Paulo/SP - Brazil.
} 


\section{CASE REPORT}

A 36-week-gestation male neonate weighing $2230 \mathrm{~g}$ was born to a 29-year-old female patient, primipara, by vaginal labor induced with oxytocin. The mother's medical history was unremarkable, except for two episodes of urinary tract infection and a morphologic ultrasound examination at 19 weeks' gestation showing exencephaly, medial labial cleft, and edema. After a breech delivery with a laceration of the umbilical cord during birth, a neonate with multiple malformations was born, with an Apgar score of 8/9/9. The neonate was referred to the neonatal ICU for palliative care. The parents were aware of the prognosis, with the malformations being incompatible with life. The karyotype analysis was normal, $46 \mathrm{XY}$ (20 cells analyzed). During the ICU stay, the neonate was placed in a heated crib, prescribed serum, analgesic, fentanyl, and midazolam. The physical examination presented heart rate of 180 beats per minute and room air oximetry of $100 \%$. The newborn evolved with grunting and died with 29 hours. An autopsy was performed.

\section{Autopsy Findings}

The ectoscopic examination showed a male neonate with multiple malformations (Figure 1). Multiple craniofacial abnormalities were observed: central nervous system and skull defects were represented by asymmetric and anteriorly placed exencephaly in fronto-parietal topography; bilateral labial cleft with distorted nostrils; and palate cleft. There was also a facial skin tag band from the right nasal ala to the edge of the skin with the exencephaly. The exophthalmos was more prominent in the right eye with hypoplasia of the eyelids and a cutaneous appendix on the temporal scalp topography was also present (Figure 2).

A thin winy-yellowish-colored membrane and areas with fibrinous material deposition coated the exposed surface of the brain. The brain showed multiple malformations with a lobulated appearance. The microscopic examination showed arachnoid-toamnion membrane adhesions, which showed signs of acute inflammation (Figure 3).

The limbs showed predominantly distal deformities such as distal amputation of the fingers in both hands and feet, oligodactyly associated to syndactyly in the left foot with evident amniotic band, ring constriction in the right leg, presence of right hyperextension and clubfoot. Upper limbs showed length discrepancies (Figure 4).

At the opening thoracic and abdominal cavities there was no abnormality in the organic topography neither in their gross examination. The weight of the organs is showed in Table 1. The heart showed foramen oval and a patent duct arteriosus. The lungs showed multiple petechiae scattered on the pleural surface and in the parenchyma (Figure 5). The microscopic examination depicted the lungs in the alveolar stage of development with multiple areas of alveolar hemorrhage. Hepatic extra medullary hematopoiesis was observed with no evidence of conspicuous nephrogenic zone in the kidneys-findings that are consistent with the 36th gestational week.
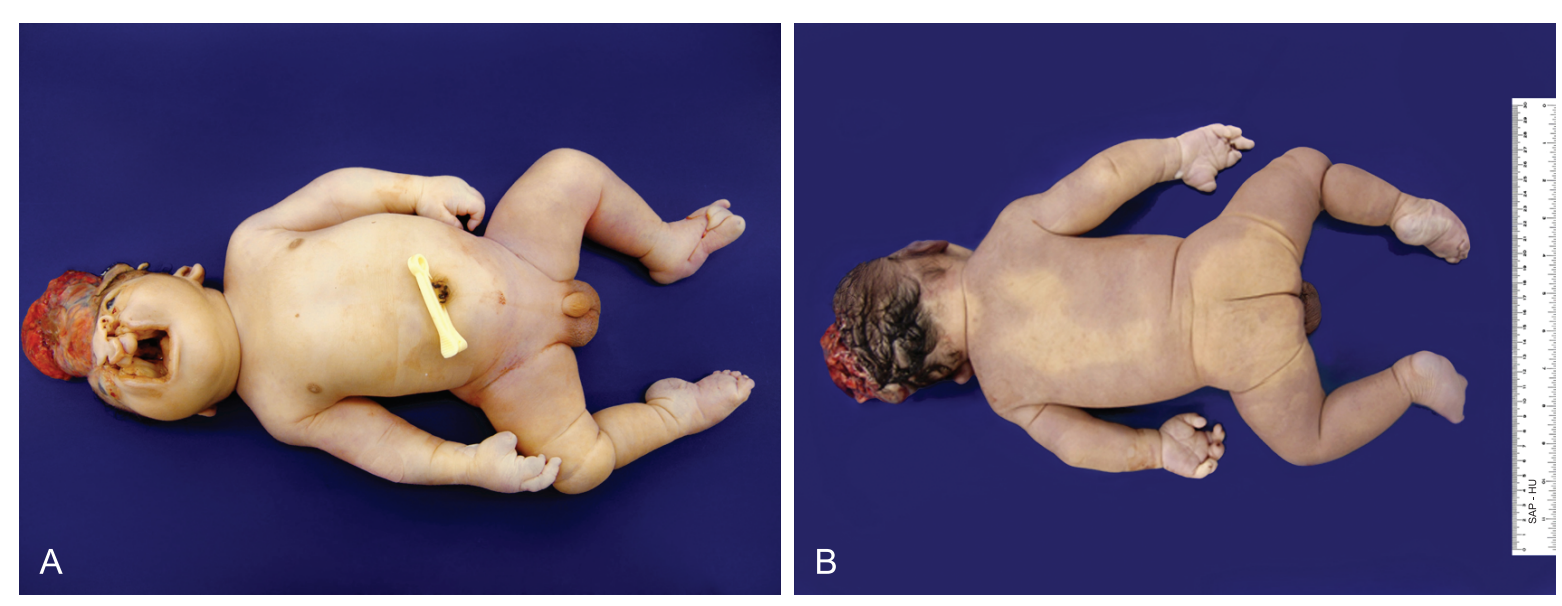

Figure 1 - Panoramic pictures of the neonate. A - Ventral sight showing multiple craniofacial malformations, mammary hypertelorism, limbs with distal deformities, and upper limb length discrepancy; B - Back view. 

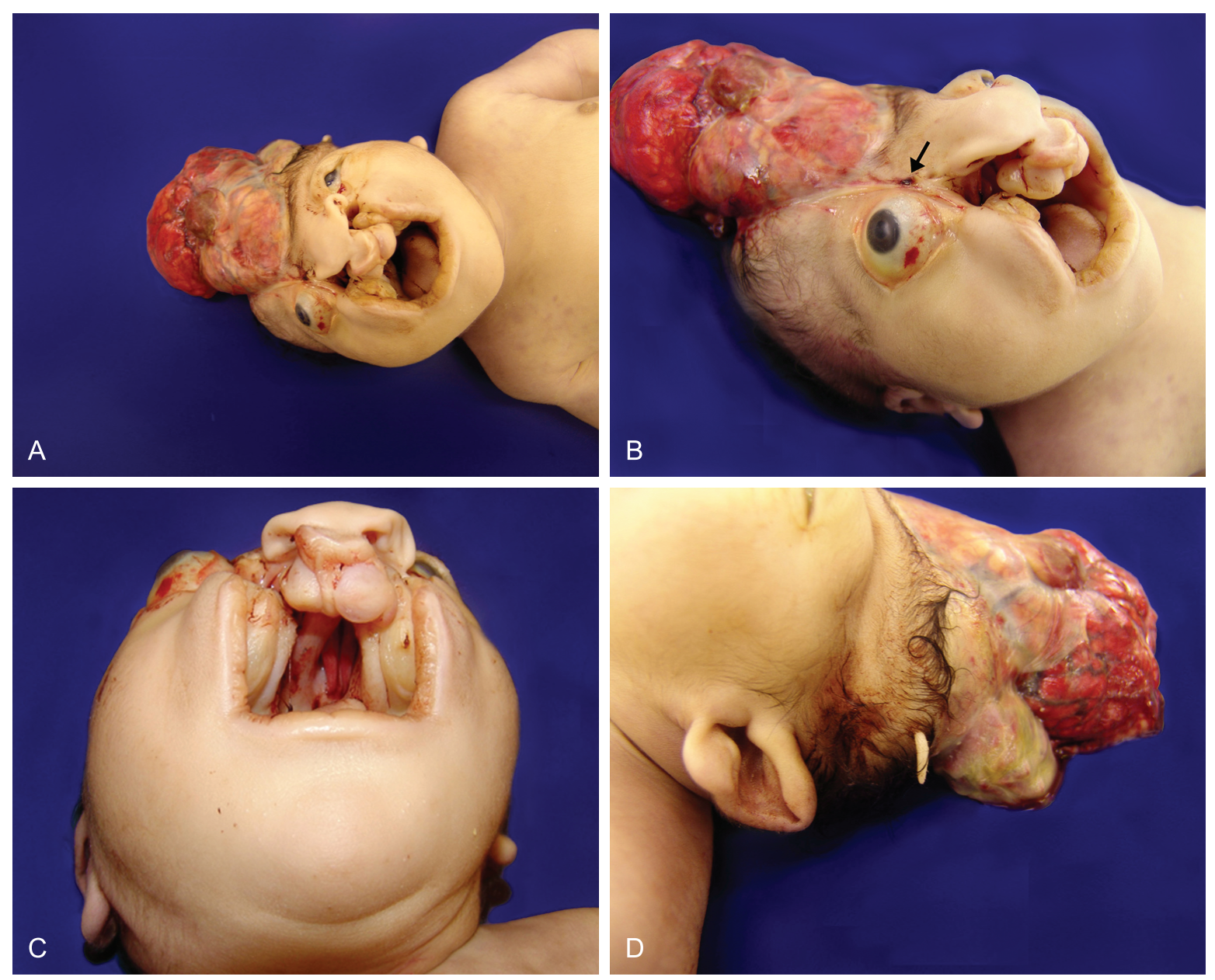

Figure 2 - Multiple craniofacial malformations. A - Exencephaly in fronto-parietal topography, bilateral labial cleft with distorted nostrils, and palate cleft; B - Facial skin tag band from the right nasal ala to the edge of the skin with the exencephaly (arrow) and right exophthalmy with hypoplasia of the eyelids; C - Bilateral labial cleft in continuity with palate cleft; D - Exencephaly with winy-yellowish-coated membranes and a skin tag on the scalp.

Table 1 - Weight of organs

\begin{tabular}{cccccc}
\hline Organ & Weight $(\mathbf{g})$ & $\mathbf{R V}(\mathbf{g})$ 36th gestational week & Organ & Weight $(\mathbf{g})$ & RV $_{(\mathbf{g})} \mathbf{3 6}^{\text {th }} \mathbf{g e s t a t i o n a l}$ week \\
\hline Thymus & 13.2 & $7.7 \pm 5.0$ & Spleen & 5.3 & $8.1 \pm 3.1$ \\
Right \& left lungs & $12.8 / 15.0$ & $36.9 \pm 17.5^{*}$ & Right \& left kidneys & $12.6 / 11.7$ & $21.7 \pm 6.8^{*}$ \\
Liver & 73.1 & $96.3 \pm 33.7$ & Pancreas & 2.8 & $2.6 \pm 0.7$ \\
Heart & 14.0 & $15.0 \pm 5.1$ & & \\
\hline
\end{tabular}

$\mathrm{RV}=$ reference value; *weight for both left and right organs.

We concluded that all malformations described above were caused by an amnion band disruption sequence.

The placenta measured $16.0 \times 13.0 \times 2.5 \mathrm{~cm}$ and weighted $343.0 \mathrm{~g}$. The marginal insertion of the membranes showed up opalescent. The umbilical cord had a central insertion and measured $40.0 \mathrm{~cm}$ in length and $1.0 \mathrm{~cm}$ in diameter, with three vases: two umbilical arteries and one vein. Over the fetal face, the blood vessels were prominent and turgid. The maternal face was complete, showing a winy staining with opalescent areas. At the histological examination, chronic infarction areas, an increased number of syncytial knots, slight villous immaturity, foci of dystrophic calcification, and foci of chronic villitis with lymphocytes, histiocytes and focal granuloma were observed (Figure 6). 

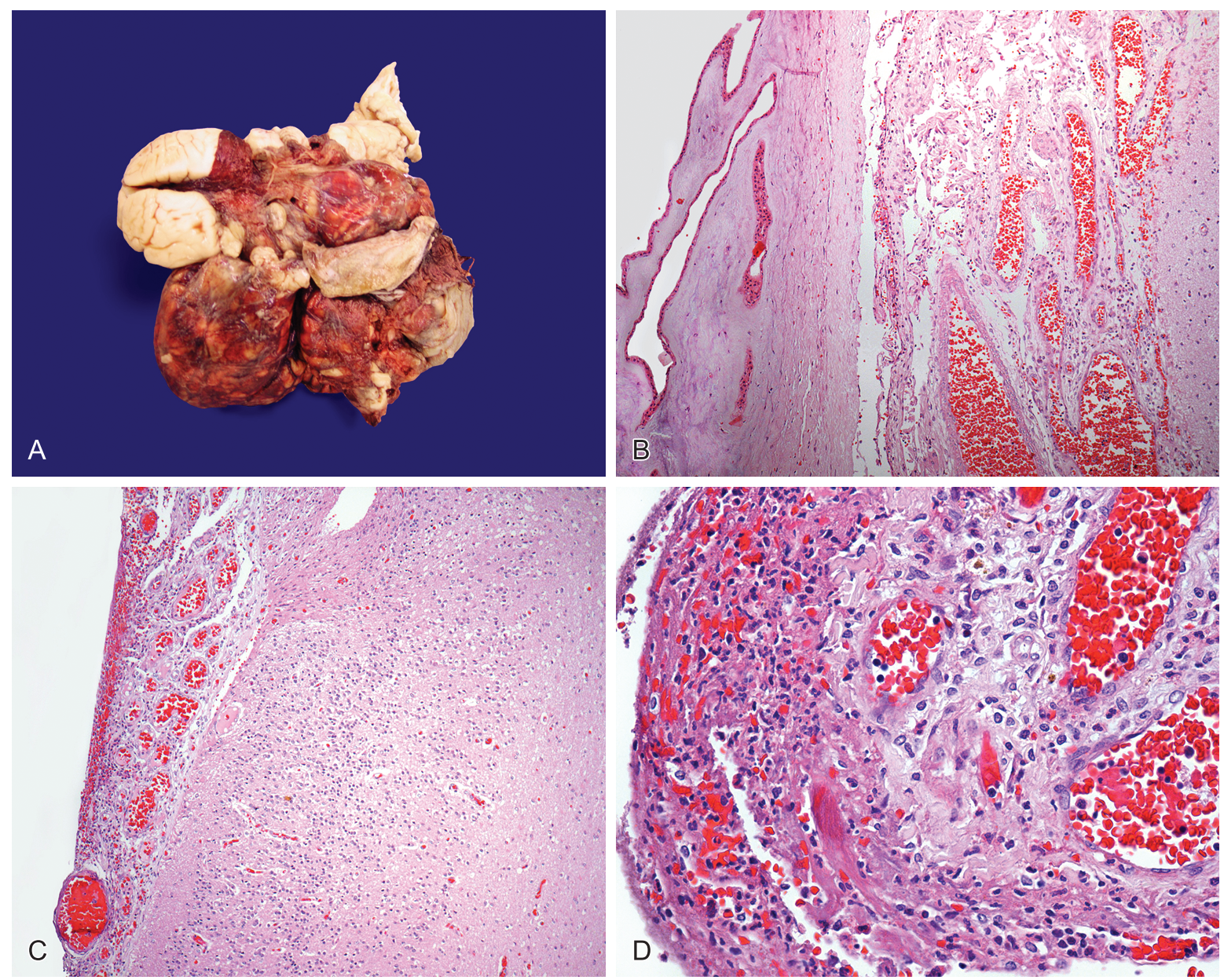

Figure 3-A - Gross examination of the brain showing multiple malformations with the lobulated appearance. Photomicrographies: B - Arachnoid-to-amnion membrane adhesion (HE 100x); C and D - Winy meninges showing acute inflammation (HE 100× and 400x, respectively).

\section{DISCUSSION}

We report a case of male neonate at 36 weeks' gestation with multiple malformations secondary to disruption of development caused by amniotic band sequence (ABS). Disruption, also called secondary malformation, is a morphologic defect of an organ, part of an organ, or a larger region of the body resulting from a breakdown of, or interference with, an originally normal development process. ${ }^{1,2} \mathrm{~A}$ classical example of disruption is an amniotic band, but it can also be caused by environmental agents such as physical and infectious agents, drugs, chemicals, and maternal conditions. ${ }^{3}$

ABS is an uncommon and heterogeneous congenital disorder caused by the entrapment of fetal parts by fibrous amniotic bands, resulting in distinctive structural abnormalities involving limbs, trunk, and craniofacial regions, of variable severity. ${ }^{4}$ The spectrum of structural anomalies varies and depends on the stage of embryonic development and the severity of the disruptive event. ${ }^{5}$ Many terms have been used as synonyms for this complex anomaly, namely: amniotic band disruption sequence, amniotic band syndrome, amniotic deformity adhesions and mutilation complex (ADAM), and limb body wall complex (LBWC).

ABS occurs in approximately 1/1200$1 / 15,000$ live births. ${ }^{4,6}$ There is a higher prevalence of ADS between previable fetuses and stillbirths, with 11.4 per 10,000 previable fetuses of less than 28 weeks' gestation $^{7}$ and 178.2 per 10,000 in fetuses from spontaneous miscarriages and induced abortions of 9-18 weeks' gestation. ${ }^{8}$

The etiology of ABS remains debatable, and its physio pathogeny still remains unknown. The amniotic cavity is generated by epiblastic cells, which differentiate into amnioblasts during the second week post conception. This cavity enlarges relative to the extraembryonic coelomic cavity until the amnion fuses with the chorionic plate by 12 weeks post conception. ${ }^{9}$ Amniotic bands occur when the amnionic membrane fails to fuse with the 

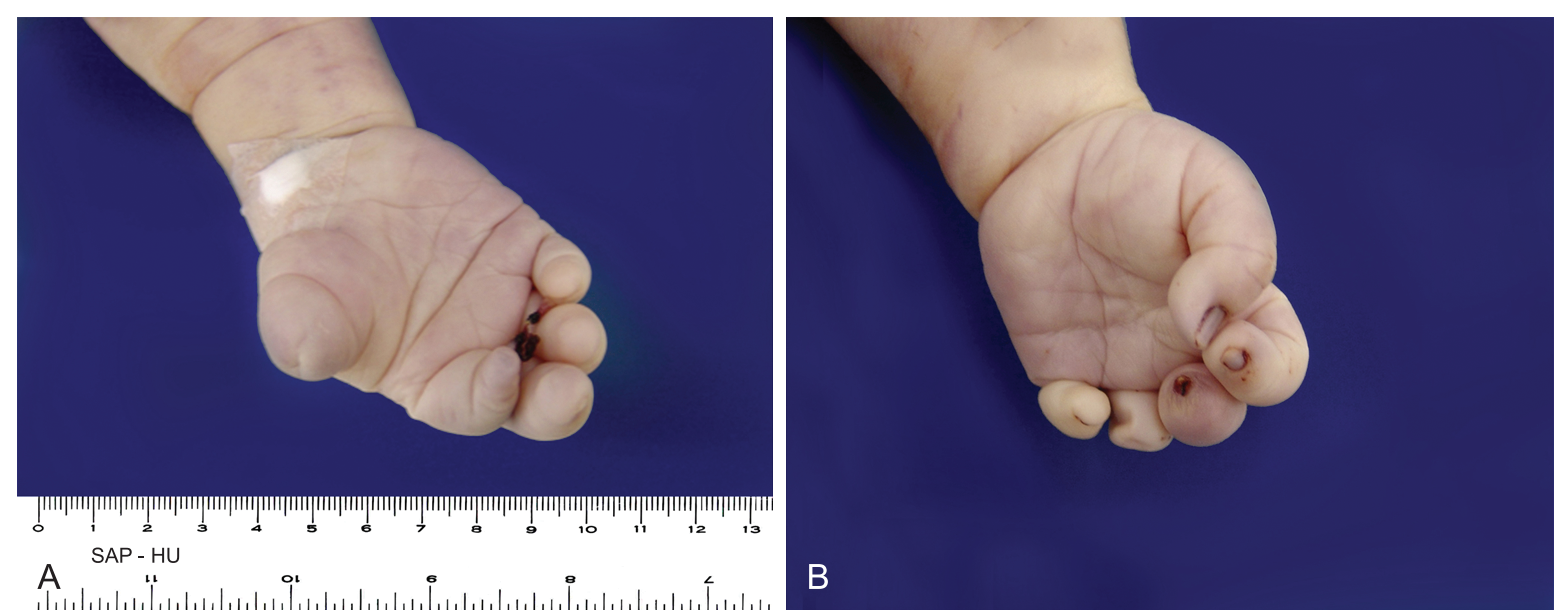
A SAP - HU

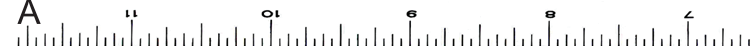
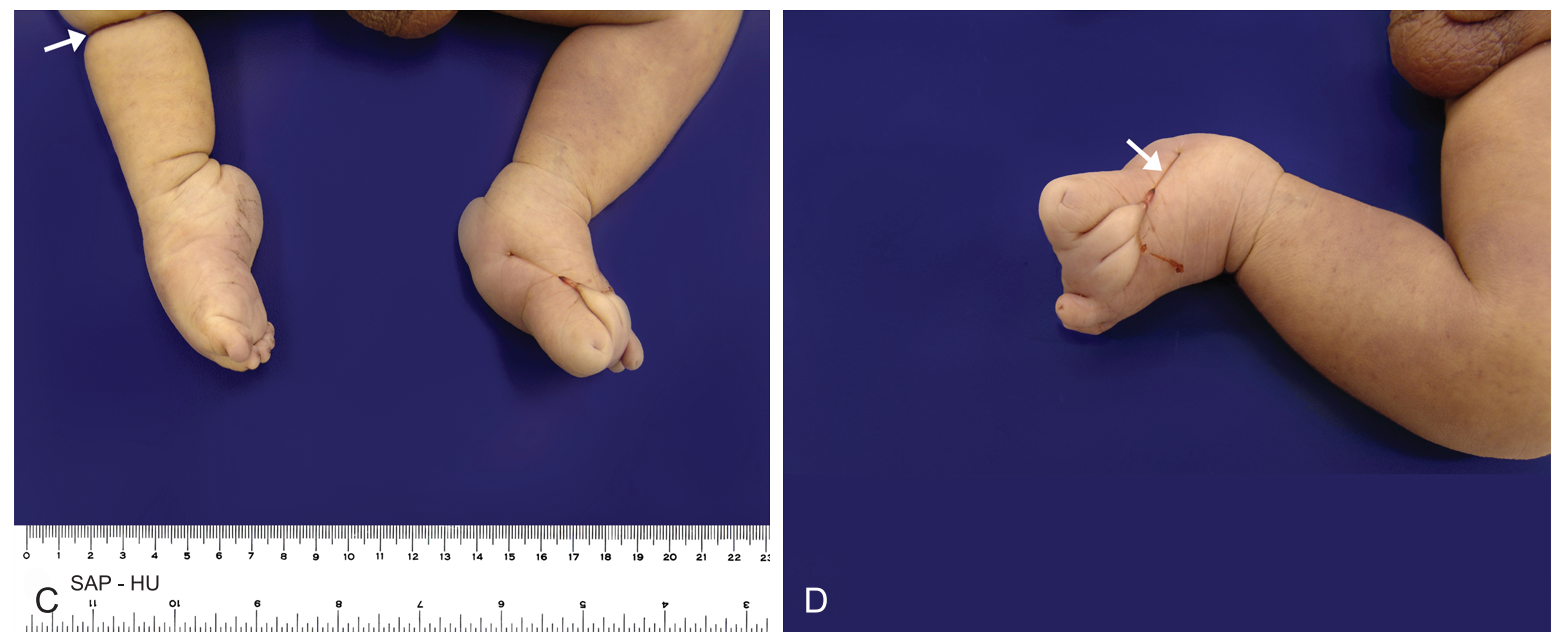

Figure 4 - Gross examination of the limbs. A and B - Distal finger amputations in both hands; C - Lower right limb ring constriction (arrow) and the presence of hyperextended right clubfoot, medial sight of the syndactyly in the left foot with evident amniotic band; D - Details of the oligodactyly associated with syndactyly in the left foot with evident amniotic band (arrow).

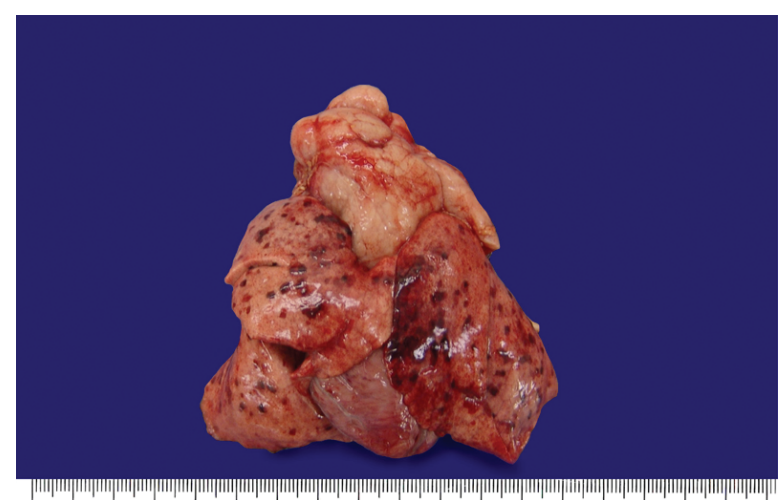

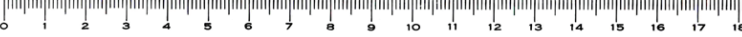
A SAP - HU

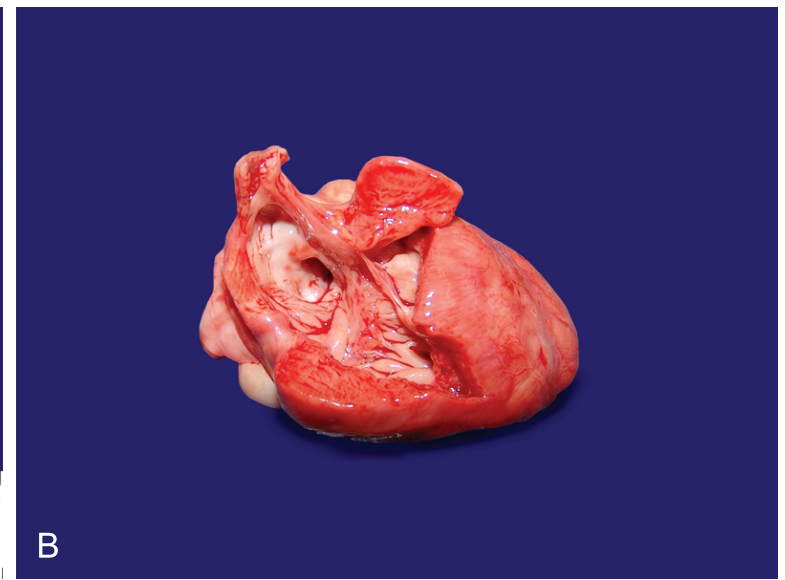

Figure 5-A - Gross examination of the intrathoracic organs monoblock showing multiple petechiae on the pleural surfaces; B - Open right cardiac chambers view showing the patent foramen oval.

chorionic plate, or when the amnion epithelium and stroma become detached from the deeper chorionic structures of the extraplacental membrane and chorionic plate. ${ }^{10}$ There are two main theories that explain the development of ABS. The first is the intrinsic theory, proposed by Streeter in 1930, 11,12 which suggests that the constriction band syndrome represents an inherent development defect in embryogenesis. The second is the extrinsic theory, and was described by Torpin in 1965.11,13 This theory proposes that an early amnion rupture is responsible for the formation of adherent bands that can constrict, entangle, and amputate limbs. As the amnion ruptures, it slips off the chorion to form the 

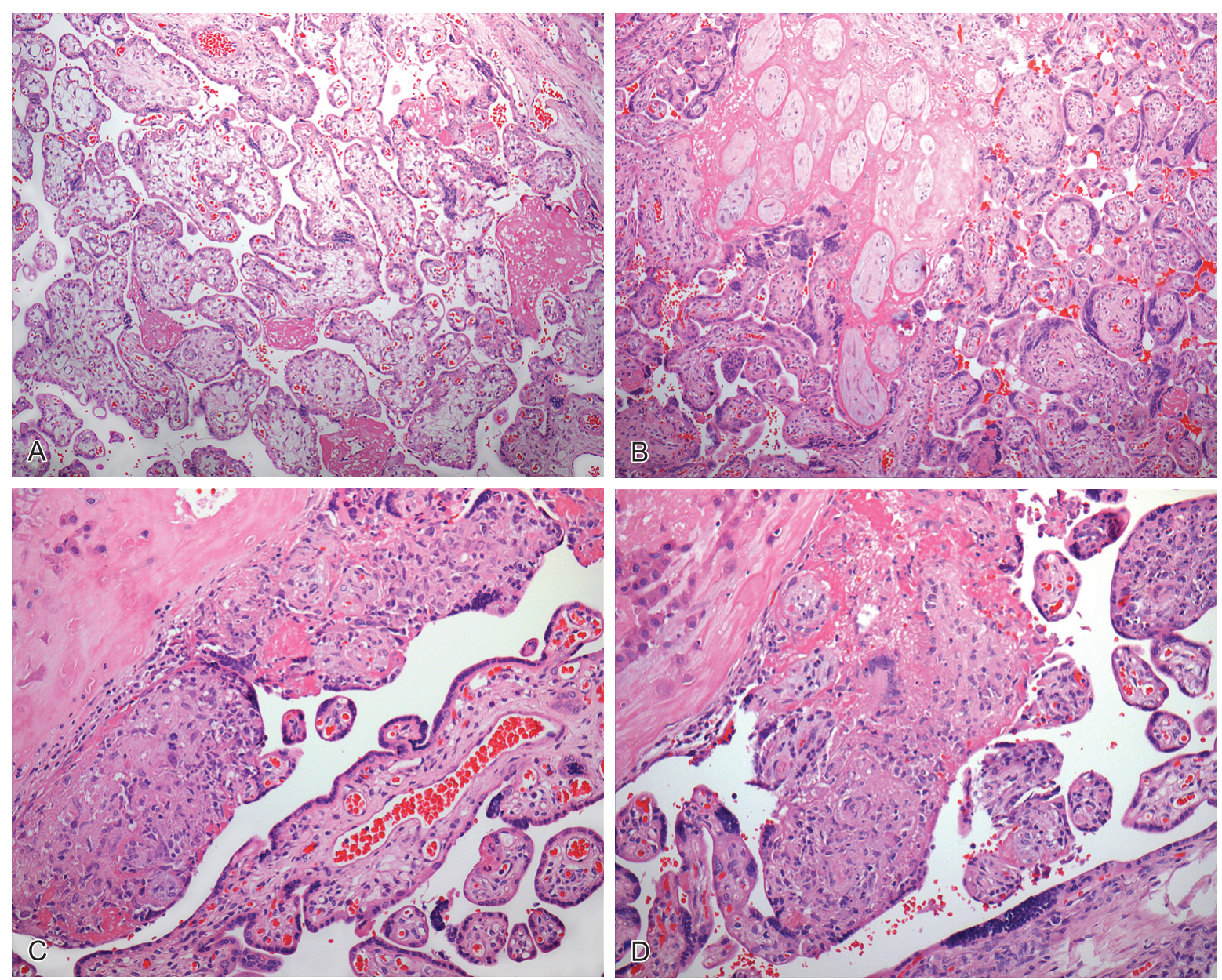

Figure 6 - Photomicrography of histologic sections of placenta. A - Slight villous immaturity (HE 100x); B - Chronic infarction areas and increased number of syncytial knots (HE 100x); C and D - Foci of chronic villitis with lymphocytes, histiocytes, and a focal granuloma near decidua (HE 200x).

detaching mesoblastic fibrous strands; thereafter it becomes entangled around the digits or limbs.

Even though the extrinsic theory seems to be more accepted, there is no agreement between different authors. Van Allen et al. ${ }^{14}$ suggested that amputations and constriction rings might be due to vascular disturbances. A prospective study conducted by Van Allen et al. ${ }^{15}$ observed, by magnetic resonance angiography in newborns with constrictions bands and limb reduction defects, vessel abnormalities in the affected limbs, such as bifurcation or trifurcation of major vessels, the absence of major vessels, atretic segments in the major limbs arteries and absent branches. ${ }^{16}$ Kalousek et al. ${ }^{17}$ divide the amnion defects into the LBWC, caused by an early defect of the amniotic sac, and ABS caused by amniotic bands. Tissue bands, sometimes running to the placental membranes are often, but not universally, observed, particularly in the mature fetus. ${ }^{18}$
Although we could not demonstrate fibrous amniotic strands in placenta, we undoubtedly observed evidence of amnion band constrictions on the neonate. The latter were represented by multiple craniofacial malformations with a facial skin tag band, arachnoid-to-amnion membrane adhesion, and ring constriction band in the limbs with distal amputations of the fingers. This finding may be in favor of the extrinsic theory.

The etiology for ABS cannot be found in most pregnancies. According to the literature, ABS has been related to young maternal age, primigravida, use of acetaminophen, abdominal trauma, chorioamnionitis, vaginal bleeding during the first trimester, abortion, intrauterine contraception, chorionic villus sampling, amniocentesis, malformation of the uterus, prematurity, and noncephalic presentation. ${ }^{4,16,19}$ Except for the episodes of urinary tract infection treatment during pregnancy, the maternal history of this case report was unremarkable. The placental examination showed 
foci of chronic villitis near the decidua, which could be related to these infectious episodes.

Nevertheless, ABS has not been linked to chromosomal abnormalities or genetic bases. Some cases have been reported in families with collagen tissue disorders, more specifically Ehler-Danlos syndrome and osteogenesis imperfecta, due to the abnormality of amnion collagen formation. ${ }^{20,21}$ Anomalies resulting from amniotic bands may simulate chromosomal abnormalities especially when neural tube defects (NTD) evolve as the exencephaly observed in this case report. NTD may present as ex- or anencephaly, iniencephaly, encephalocele, meningomyelocele, or spina bifida in association with cranioschisis. NTD was observed in $3.6-6.7 \%$ of the intact embryos in cases of miscarriage. Most of these cases were chromosomally abnormal. ${ }^{22}$ Folic acid deficiency is also part of the pathology of NTD. ${ }^{23}$ Moreover, the midline facial defects observed in this case, with labial and palatal clefts, have a differential diagnosis with trisomy 13 and trisomy $18,{ }^{24}$ but the karyotype study was normal.

\section{CONCLUSION}

The prognosis of $A B S$ depends on the type, the number of disruptions, and the stage of embryonic development. Newborns with early ABS who have severe neural tube and body-wall defects rarely survive. Surgical treatments for functional and aesthetic restoration may be indicated in some cases. Treatment must be individualized and the timing of surgery is determined by the disease severity and predicted skeletal growth. The possible surgical treatment, described in the literature, encompass cleft lip repair, cleft palate closure, distraction osteogenesis for severe micrognathia, ocular surgery for colobomas, hand surgery, and craniofacial surgery as fronto-orbital remodeling during the first months of life..$^{11,25}$

Actually, current improvements in prenatal diagnosis and fetoscopic surgical techniques may eventually allow in utero treatment of ABS. ${ }^{26,27}$ Fetal limb abnormality interventions associated with ABS are described in fetuses with abnormal but present arterial Doppler flow to the distal limb. After evaluating the benefits and high risks of in utero therapy, the constriction band could be released and blood flow re-established. However, this "band lysis" surgery remains a high-risk procedure, with the occurrence of premature rupture of membranes in $71 \%$ of cases. ${ }^{26}$

The authors describe a case of ABS with multiple malformations with severe craniofacial abnormalities, oligodactyly, syndactyly, and limb distal amputation. The recognition of malformations described herein, secondary to ABS, is important in genetic counseling to prevent misdiagnosis between chromosomal and secondary disruption disorders.

\section{REFERENCES}

1. Cohen Junior MM. Craniofacial abnormalities. In: GilbertBarness E, editor. Potter's pathology of the fetus, infant and child. 2nd ed. Philadelphia: Mosby-Elsevier; 2007. p. 894. PMid:18087839.

2. Cohen Junior MM. The child with multiple birth defects. 2nd ed. New York: Oxford University Press; 1997.

3. Frias JL, Gilbert-Barness E. Disruptions. In: Gilbert-Barness E, editor. Potter's pathology of the fetus, infant and child. 2nd ed. Philadelphia: Mosby-Elsevier; 2007. p. 135-212.

4. Kahramaner Z, Cosar H, Turkoglu E, et al. Amniotic band sequence: an extreme case. Congenit Anom (Kyoto). 2012;52:59-61. PMid:21039912. http://dx.doi. org/10.1111/j.1741-4520.2010.00301.x

5. Gilbert-Barness E, Van Allen MI. Vascular disruptions. In: Gilbert-Barness E, editor. Potter's pathology of the fetus, infant and child. 2nd ed. Philadelphia: Mosby-Elsevier; 2007. p. 200.

6. Poeuf B, Samson P, Magalon G. Amniotic band syndrome. Chir Main. 2008;27:136-47. PMid:18948051. http://dx.doi. org/10.1016/j.main.2008.07.016

7. Byrne J, Blanc WA, Baker D. Amniotic band syndrome in early fetal life. Birth Defects Orig Artic Ser. 1982;18:43-58. PMid:7188597.

8. Kalousek DK, Bamforth S. Amnion rupture sequence in previable fetuses. Am J Med Genet. 1988;31:63-73. PMid:3223500. http://dx.doi.org/10.1002/ajmg.1320310110

9. Oligny LL. Disorders of the anterior thoracic and abdominal walls. In: Potter's pathology of the fetus, infant and child. 2nd ed. Gilbert-Barness E, editor. Philadelphia: Mosby-Elsevier; 2007. p. 935.

10. Boyd TK, Redline RW. Pathology of the placenta. In: GilbertBarness E, editor. Potter's pathology of the fetus, infant and child. 2nd ed. Philadelphia: Mosby-Elsevier; 2007. p. 663. 
11. Kawamura K, Chung KC. Constriction Band Syndrome. Hand Clin. 2009;25:257-64. PMid:19380064. http://dx.doi. org/10.1016/j.hcl.2008.10.007

12. Streeter GL. Focal deficiencies in fetal tissues and their realtion to intrauterine amputations. Contrib Embryol Carnegie Inst. 1930;22:1-44.

13. Torpin R. Amniochorionic mesoblastic fibrous strings and amniotic bands. Am J Obstet Gynecol. 1965;91:65-75. PMid:14245093.

14. Van Allen MI, Curry C, Walden CE et al. Limb-body wall complex: II. Limb and spine defects. Am J Med Genet. 1987;28:549-65. PMid:2962494. http://dx.doi. org/10.1002/ajmg.1320280303

15. Van Allen MI, Siegel-Bartelt J, Dixon J et al. Constriction bands and limb reduction defects in two newborns with fetal ultrasound evidence for vascular disruptions. Am J Med Genet. 1992;44:598-604. PMid:1481816. http://dx.doi. org/10.1002/ajmg.1320440513

16. Cignini P, Gloriandino C, Padula F, et al. Epidemiology and risk factors of amniotic band syndrome, or ADAM sequence. J Prenat Med. 2012;6:59-63. PMid:23272276 PMCid:3530965.

17. Kalousek DK, Fitch N, Paradice BA. Pathology of the human embryo and previable fetus: an atlas. New York: SpringerVerlag; 1990. PMCid:54875. http://dx.doi.org/10.1007/978$1-4757-2111-9$

18. Keeling JW, Kjaer I. Diagnostic distinction between anencephaly and amnion rupture sequence bsed on skeletal analysis. J Med Genet. 1994;31:823-9. http:// dx.doi.org/10.1136/jmg.31.11.823

19. Werler MM, Louik C, Mitchell AA. Epidemiologic analysis of maternal factors and amniotic band defects. Birth Defects Research. 2003;67:8-72.
20. Burk CJ, Aber C, Connelly EA. Ehlers-Danlos syndrome type IV: keloidal plaques of the lower extremities, amniotic band limb deformity, and a new mutation. J Am Acad Dermatol. 2007;56:53-4. PMid:17224388. http://dx.doi. org/10.1016/j.jaad.2006.11.008

21. Van Der Rest M, Hayes A, Marie P, et al. Lethal osteogenesis imperfecta with amniotic band lesions: collagen studies. Am J Med Genet. 1986;24:433-46. PMid:3728562. http://dx.doi. org/10.1002/ajmg.1320240306

22. Coerdt W, Miller K, Holzgreve W, et al. Neural tube defects in chromosomally normal and abnormal human embryos. Ultrasound Obstet Gynecol. 1997;10:410-5. PMid:9476327. http://dx.doi.org/10.1046/j.1469-0705.1997.10060410.x

23. Bower C. Prevention of neural tube defects with folate. J Paediatr Child Health. 2013;49:2-4. PMid:23282182. http:// dx.doi.org/10.1111/jpc.12069

24. Gilbert-Barness, Oligny LL. Chromosomal abnormalities. In: Gilbert-Barness E, editor. Potter's pathology of the fetus, infant and child. 2nd ed. Philadelphia: Mosby-Elsevier; 2007. p. 213-75.

25. Morovic CG, Berwart F, Varas J. Craniofacial anormalies of the amniotic band syndromes in serial clinica cases. Plast Reconstr Surg. 2004;113:1556-62. http://dx.doi. org/10.1097/01.PRS.0000117185.25173.38

26. Hüsler MR, Wilson RD, Horii SC, et al. When is fetoscopic release of amniotic bands indicated? Review of outcome of cases treated in utero and selection criteria for fetal surgery. Prenat Diagn. 2009;29:457-63. PMid:19235736. http://dx.doi.org/10.1002/pd.2222

27. Neuman J, Calvo-Garcia MA, Kline-Fath BM, et al. Prenatal imaging of amniotic band sequence: utility and role of fetal MRI as an adjunct to prenatal US. Pediatr Radiol. 2012;42:544-5. PMid:22134536. http://dx.doi.org/10.1007/s00247-011-2296-8

\section{Conflict of interest: None}

Submitted on: 21 ${ }^{\text {st }}$ December 2012

Accept on: $5^{\text {th }}$ March 2013

Correspondence: Serviço de Anatomia Patológica Hospital Universitário da Universidade de São Paulo

Av. Prof. Lineu Prestes, 2565 - Cidade Universitária - São Paulo/SP - Brazil CEP 05508-900 - Phone: +55 (11) 3091-9384

E-mail: crisrf@hu.usp.br 